\title{
İş Kazası Sonucu Maluliyet Tayinine Konu Olan Üst Ekstremite Yaralanmaları: Üç Olgu Sunumu
}

\author{
Upper Extremity Injuries Due to Work Accidents in Work Accident Disability \\ Assessments: Three Case Reports
}

Serbülent Kılıç, Sündüz Adıyaman, Fatih Sezer, Gürol Cantürk

Ankara Üniversitesi Tıp Fakültesi Adli Tıp Anabilim Dalı, Ankara

\begin{abstract}
Özet
İş kazaları Adli tıp’ın resmi bilirkişilik hizmetini sunduğu önemli bir alandır. Farklı şehirlerde bulunan mahkemeler tarafindan anabilim dalımızdan iş kazası geçiren üç şahsın bu olay sebebi ile oluşabilecek maluliyet oranı ve iş görmezlik süresi hususlarında rapor hazırlanması istenmiştir.

Şahısların muayenesinin yapılması ve tıbbi evrakının tetkik edilmesinden sonra üç olgumuzda da iş kazası sonucu üst ekstremitede yaralanma meydana geldiği anlaşılmıştır. Olgularımızdan birinde el parmaklarının amputasyonu, diğer olgularda sinir hasarı ve hareket k1sitlllı̆̆ 1 tespit edilmiştir.

Önemli bir halk săğlı̆̆ sorunu olan iş kazaları; iş gücü kaybına, maddi zarara, kalıcı sakatlıklara ve ölümlere sebep olabilmektedir. Bu tip kazalarda üst ekstremite travmaları sık görülmekte olup karakteristik yaralanma bulguları mevcuttur. Bu çalışmada; adli rapor hazırlayan ve bilirkişilik görevini yürüten adli tıp uzmanlarının, iş kazalarının karakteristik yaralanma bulguları ve iş kazaları ile ilgili adli tıbbi rapor hazırlanmasının önemi konularına dikkatinin çekilmesi amaçlanmıştır.

Anahtar Kelimeler: Adli tıp; Amputasyon; El yaralanması; İş kazas1; Maluliyet; Üst ekstremite yaralanması.
\end{abstract}

\section{Giriş}

İş kazaları; iş yerinde ya da işin devam ettirilmesi sebebiyle ortaya çıkan ruh veya beden bütünlüğüne zarar veren ya da ölüme neden olan olgulardır (1). Adli Tıp'ın bilirkişilik hizmetini yürüttüğü önemli bir alan olan iş kazaları, tüm gelişmekte olan ülkelerdeki gibi ülkemizde de halen büyük bir sorundur. Mahkemeler tarafindan Anabilim Dallarından iş kazaları ile ilgili kusur oranları ve oluşan bireysel maluliyetler hakkında resmi mütalaa istenmektedir. Ülkemizde 2014 yılında kayıtlara geçen iş kazası geçiren sigortalı sayısı 221.366'dır (2). İş kazaları ile ilgili olarak yasal mevzuat açığı nedeniyle kanun koyucu tarafindan 2012 yilında Resmi Gazete'de ‘6331 Sa-

Sorumlu Yazar: Serbülent Kılıç

Ankara Üniversitesi Tip Fakültesi Adli Tip Anabilim Dalı, Ankara E-posta: kilicserbulentmd@gmail.com

Geliş:24.11.2015 Düzeltme:24.01.2016

Kabul:04.02.2016

\begin{abstract}
Industrial accident is an area that forensic specialists expertise on. The courts in different cities asked for reports about three injury cases due to industrial accidents from our department of forensic medicine. Each report should include the disability rate and the duration of unfunctionality.

The history and physical examination of each case revealed the diagnosis of upper extremity injury due to industrial accident. The first case had few amputations on the hand fingers, and the other cases had paralysis and ancylosis.

Industrial accident, a significant problem of public health can causes loss of labour and money, disabilities and even death. Injuries of the upper extremity with the characteristic injury findings are often come across in such accidents. Our aims to present the current three cases are to have forensic medicine specialists be aware of characteristic signs of industrial accidents and the importance of the expert reports preparation concerning industrial accidents.
\end{abstract}

Keywords: Forensic Medicine; Amputation; Hand Injury; Industrial Accident; Disability; Upper Extremity Injury.

yılı İş Sağlığı ve Güvenliği Kanunu’ yayınlanarak yürürlüğe girmiştir (1). Kanunun yayınlanmasından günümüze dek geçen süreçte iş kazalarında bir azalma olmadığı göze çarpmaktadır. İş kazaları acil servise yapılan müracaatların yaklaşık \% 2'sini oluşturmaktadır (3). Kayıt dışı kalan vakalar da göz önüne alındığında bu tip kazaların azımsanmayacak bir halk sağlı̆ğ sorunu olduğu söylenebilir.

İş kazalarında üst ekstremite yaralanmasına sıkça rastlanmaktadır. 528 iş kazası olgusunu kapsayan bir çalışmada; olguların yaklaşık $2 / 3$ 'ünün üst ekstremitesinin travmaya maruz kaldığı belirtilmektedir (3). Özellikle el; üst ekstremitenin en az korunaklı kısmı olup en çok travmaya maruz kalan parçasıdır (4). El; on dördü falankslar olmak üzere yirmi yedi kemikten oluşan, intrinsik ve ekstrinsik kaslarla sarılı olan, median, radial ve ulnar sinirler ile innervasyonu sağlanan bir organdır (5). Elin travmaya maruz kalması ile el kemiklerinde kırık ve çıkık, sinir hasarları, 
damar yaralanmaları, pulpa kaybı, amputasyon, yumuşak doku kaybi gibi tablolar meydana gelebilmektedir (6).

İş kazaları sonucu meydana gelen el yaralanmalarının özellikle tecrübesiz işçilerde ve haftanın ilk çalışma günü daha sık görüldüğü iddia edilmektedir (7). İş kazaları önemli ölçüde maddi ve iş gücü kaybına da yol açmaktadır. İsviçre'de yapılan bir çalışmada el travması sonucu tedavi edilen hastaların ortalama 45,5 gün sonra işlerine dönebildikleri bildirilmektedir (8). İsveç’te yap1lan bir çalışmada ağaç işlerinde meydana gelen iş kazaları sonucu ortaya çıkan el ve kol yaralanmalarının yılda yaklaşık 3 milyon euro kayba yol açtığı belirtilmektedir (9). Polonya'da yapılan bir çalışmada ise bir el yaralanmasının yaklaşık 6100 dolar ekonomik maliyete yol açtığı belirtilmektedir (10). İngiltere'de el yaralanmalarının yılda 100 milyon poundun üzerinde bir maddi kayba yol açtı ̆̆

Üst ekstremite yaralanmalarının etiyolojisi incelendiğinde iş kazaları sonucu meydana gelen travmaların önemli bir yer tuttuğu görülmektedir. 300 el yaralanma olgusunu kapsayan bir çalışmada olguların \% 36'sının sanayi alanında meydana geldiği belirtilmektedir (12). El yaralanması ile başvuran ve yatarak tedavi edilen 1205 olgunun etiyolojisinin incelendiği bir çalışmada ise; yaralanmaların kabaca \% 18'inin kesici delici alet, hızar, pres makinesi ve diğer nedenlerle oluşan iş kazası olduğu, olguların yaklaşık \% 87'sinin erkek olduğu belirtilmektedir (13). Acil servise el yaralanması şikayeti ile başvuran 196 olgunun incelendiği bir çalışmada; olguların yaklaşık \% 55 'inin işçi olduğu, yaş grubu olarak en sık 2. dekaddaki bireylerin maruz kaldığı, olguların kabaca onda birinde amputasyon meydana geldiği belirtilmektedir (13). 185 üst ekstremite yaralanma olgusunu kapsayan bir çalışmada; çalışmalarında yer alan genç yaş grubundaki olguların en sık mobilya sektöründe çalışırken bu travmaya maruz kaldığı belirtilmektedir (14).

İş kazası sonucu gelişen üst ekstremite yaralanmalarında; beceri gerektiren işler yapılırken bu tür kazalara maruz kalındığı düşünüldüğünde, dominant olarak kullanılan tarafın daha sık etkileneceği söylenebilir. Endüstri alanında meydana gelen 112 el travmalı olguyu kapsayan bir çalışmada; olguların \% 57'sinde dominant olarak kullandığı elin yaralandığı belirtilmektedir (15).

Çalışmamızı paylaşım amacımız; ülkemiz gibi gelişmekte olan ülkelerde büyük bir sorun olmayı sürdüren ve adli vaka olarak değerlendirilen iş kazalarına dikkat çekmek ve iş kazası sonucunda farklı maluliyetler meydana gelmiş üç olgumuzun tıbbi durumu belirtilerek, iş kazası sebebiyle meydana gelen üst ekstremitede yaralanmalarını incelemektir. Çalışmamıza konu olan üç olgu hakkında farklı mahkemeler tarafından Anabilim Dalımızdan iş kazası geçiren üç kişinin bu olay sebebi ile oluşabilecek maluliyet oranı ve iş görmezlik süresi hususlarında rapor hazırlanması istenilmesi üzerine şahısların muayenesi yapılarak ekte gönderilen dosyaları tetkik edilmiştir.

\section{Olgu \\ Olgu 1}

27 yaşındaki kadın olgumuz muayenesinde; silikon yastık fabrikasında çalışırken sağ elini iş makinesine kaptırdığını ve yaralandığını, ikamet ettiği şehirdeki üniversite hastanesi'ne başvurduğunu, sağ elinden iki kez opere olduğunu, evli ve 3 çocuğunun olduğunu, ev işlerine kızının yardım ettiğini, ailesiyle arasının iyi olduğunu, psikiyatrik tedavi gördüğünü belirtti. Fizik muayenede; sağ el 2. parmak interphalangeal eklemden ampute, sağ el 3. parmak interphalangeal corpustan ampute, sağ el 4. parmak interphalangeal eklemden ampute, sağ el sirtında $2 \mathrm{~cm}$ ve üç adet $1 \mathrm{~cm}$ ebadında skar olduğu, sağ el 5. parmak dorsal yüzde $2 \mathrm{~cm}$ ebadında skar olduğu, hastada hafif derecede psikiyatrik bulgularının mevcut olduğu tespit edildi. Olgumuzun kaza sonrası başvurduğu Üniversite Hastanesi'ne ait raporda: iş kazası sonucu parmakta ve elde amputasyon tanısı aldığı; aynı hastaneye ait kazadan 5 y1l sonrası tarihli Psikiyatri Anabilim Dalı Raporu'nda: tedavi ile işlevselliği kısmen düzelen uyum bozukluğu tanısı aldığı; belirtilmektedir. Olgumuzun tıbbi evrakı incelendiğinde; şahsın kaza sonrası başvurduğu Üniversite Hastanesi Psikiyatri Anabilim Dalı'na kaza sonrası iki yılı kapsayan çok sayıda başvurusu olduğu ve uyum bozukluğu, depresif nöbet, ağır stres reaksiyonu tanıları aldığı görülmüş olup Anabilim dalımızda yapılan muayenesinde post travmatik stres bozukluğu (PTSB) bulgularına rastlanılarak psikiyatri konsültasyonu istenilmiştir. Tarafımıza iletilen Psikiyatri Anabilim Dalı'nın raporunda da PTSB tanısı vurgulanmıştır.

Anabilim Dalımızda hazırlanan raporda olgumuzun bahsi geçen kaza sonucu meydana gelen yaralanmasından ötürü oluşan maluliyetinin hesaplanmasında 11.10.2008 tarihli ve 27021 sayılı Resmî Gazete'de yayımlanan Sosyal Sigortalar Kurumu Sağlık İşlemleri Tüzüğü esas alınmıştır. Şahsın olay anındaki yaşı:27, MGN:1, post travmatik stres bozukluğu (şikayetleri ölçüsünde hafif düzeyde bulguları olan ve gerekli orantılama yapılarak) için A cetveli I. Liste ASN:16-A-a AAÖ: 45, sağ el 2.parmaktaki arıza için IX. Liste ASN:2-c-ca AAÖ: 6, sağ el 3.parmaktaki arıza için IX. Liste ASN:3-c-ca AAÖ: 3, sağ el 4.parmaktaki arıza için IX. Liste ASN:4-c-ca AAÖ: 1, sağ el 5.parmaktaki arıza için XI. Liste ASN:5-B-b-ba AAÖ:1, SİGS: A olarak alındığında ve Balthazard formülü uygulandığında vücut genel çalışma gücünden kayıp oranının: \% 32,2 (yüzdeotuzikivirgüliki) olarak hesaplandığı ve 6 (altı) ay süre ile iş göremezlik halinde kaldığı, kanaatinde bulunduğumuz belirtilmektedir. 


\section{Olgu 2}

31 yaşındaki erkek olgumuz muayenesinde; iş yerinde sağ kolunu makine kestiğini, sağ elini ince işlerde kullanamadığını, psikiyatriye gitmediğini açıkladı. Fizik muayenede; sağ kol medialinde 6 x $10 \mathrm{~cm}$ skar, sağ kol medialinden ön kola uzanan $20 \times 5 \mathrm{~cm}$ skar, sağ el dorsalinde $8 \times 1 \mathrm{~cm}$ ve $8 \times 0,5 \mathrm{~cm}$ skarlar olduğu, sağ kol ve ön kol motor fonksiyonlarının normal olduğu, sağ elde hipoestezi tariflediği, sağ el motor kuvvetin $3 / 5$ olduğu, sağ ön kol ulnar bölgede hipoestezi tarif ettiği, sağ elde atrofik görünüm olduğu, üst ekstremite eklem hareket açıklıklarının normal olduğu, sağ kolunu dominant olarak kullandığı anlaşıldı. Olgumuza ait evrakın tetkikinde; Üniversite Hastanesine ait raporda; iş kazası sonucu sağ üst ekstremite dirsekten itibaren kol medialinden itibaren aksiller çukura uzanan açık yarası olduğu, "brakiyal arter yaralanmas1, üst kol düzeyinde median sinir yaralanmas1, üst kol düzeyinde ulnar sinir yaralanması" tanıları ald1ğ1, ameliyat notlarına göre; sağ kolda mevcut yara yerinde; ön grup kasları kesik, N.ulnaris, N. Medianus ve N. Muskulokutaneus'un kesik izlendiği, brakiyal arterin sütüre edilmiş olduğu, sinirlerinin onarıldığı, brakiyal venin de onarıldığı, kazadan yaklaşık 2 ay sonra ise; EMG raporunda; sağ üst ekstremite lezyon distalinden itibaren median ve ulnar sinirin total aksonal hasarının mevcut olduğu belirtilmektedir.

Anabilim Dalımızda hazırlanan raporda olgumuzun bahsi geçen kaza sonucu meydana gelen yaralanmasından ötürü oluşan maluliyetinin hesaplanmasında 11.10.2008 tarihli ve 27021 sayılı Resmî Gazete'de yayımlanan Sosyal Sigortalar Kurumu Sağlık İşlemleri Tüzüğü esas alınmıştır. Şahsın OAY:31, MGN:1, sağ üst ekstremite sinir arızası için A Cetveli VII. Liste ASN: 19-A, AAÖ: 57 (gerekli orantılama yapılarak), SİGS: A olarak alındığında vücut genel çalışma gücünden kayıp oranının: \% 56 (yüzde ellialtı) olarak hesaplandığı ve 10 (on) ay süre ile iş göremezlik halinde kaldığ belirtilmektedir.

\section{Olgu 3}

54 yaşındaki erkek olgumuz muayenesinde; mobilya montajı yaptığını, koruma sistemi olmayan testerede kapı pervazı keserken makinenin parçayı firlattığını, o sırada sağ başparmağının kesildiğini, şantiye doktorunun ilk müdahaleyi yaptığını hastaneye götürüldügünü, hastanede sinirlerin koptuğunu söylediklerini, sağ el 1. parmak distal interphalengeal ekleme dikiş atıldığını ve platin takıldığını, aynı gün taburcu olduğunu, sonrasında fizik tedavi ve rehabilitasyon aldığını, iş yaparken sağ elini kullandığı, tedavisinin tamamlandığını ve şu an ilaç kullanmadığını belirtti (Resim 1.). Fizik muayenede; sağ el başparmak distal interphalengeal eklemde radial bölgede
$5 \times 3 \mathrm{~mm}$ ve 8 x $1 \mathrm{~mm}$ uzunluklarında deri seviyesinde, deriden açık renkli, ameliyat skarı; başparmak distalinde plantar bölge-distalde doku kaybı gözlendi; şahsın sağ el başparmak distal interphalengeal eklemi $55^{\circ}$, sol el distal interphalengeal eklemi $80^{\circ}$ fleksiyon yapabiliyor. Sağ el başparmak distal interphalengeal eklemde $25^{\circ}$ hareket k1sitlılığı tespit edildi.

Olgumuzun tıbbi evrakı incelendiğinde; şahsın kaza sonrası başvurduğu Eğitim ve Araştırma Hastanesi Engelli Sağlık Kurulu Raporunda: sağ el 1. Parmak distalinde volar yüzde yaklaşık 1 x 2 cm'lik doku defekti olduğu, distal interphalengeal eklemde yaklaş1k $10^{\circ}$ hareket mevcut olduğu, 1. Parmakta şişlik ve dokunmakla hassasiyet olduğu; ilgili raporda crush injury-parmakta hareket kayb1 teşhisiyle şahsın özür durumuna göre tüm vücut fonksiyon kaybının \% 5 olduğunun belirtildiği görülmüştür. Anabilim Dalımıza ait raporda farklı maluliyet oranının tespit edilme nedeni; 11.10.2008 tarihli ve 27021 sayılı Resmî Gazete'de yayımlanan Sosyal Sigortalar Kurumu Sağlık İşlemleri Tüzüğü esas alınmasıdır. Oysaki Engelli Sağlık Kurulu Raporları '30.03.2013 tarihli ve 28603 sayılı Resmî Gazete'de yayımlanan Özürlülük Ölçütü, Sınıflandırması ve Özürlülere Verilecek Sağlık Kurulu Raporları Hakkında Yönetmelik' deki esaslara göre hazırlanmaktadır.

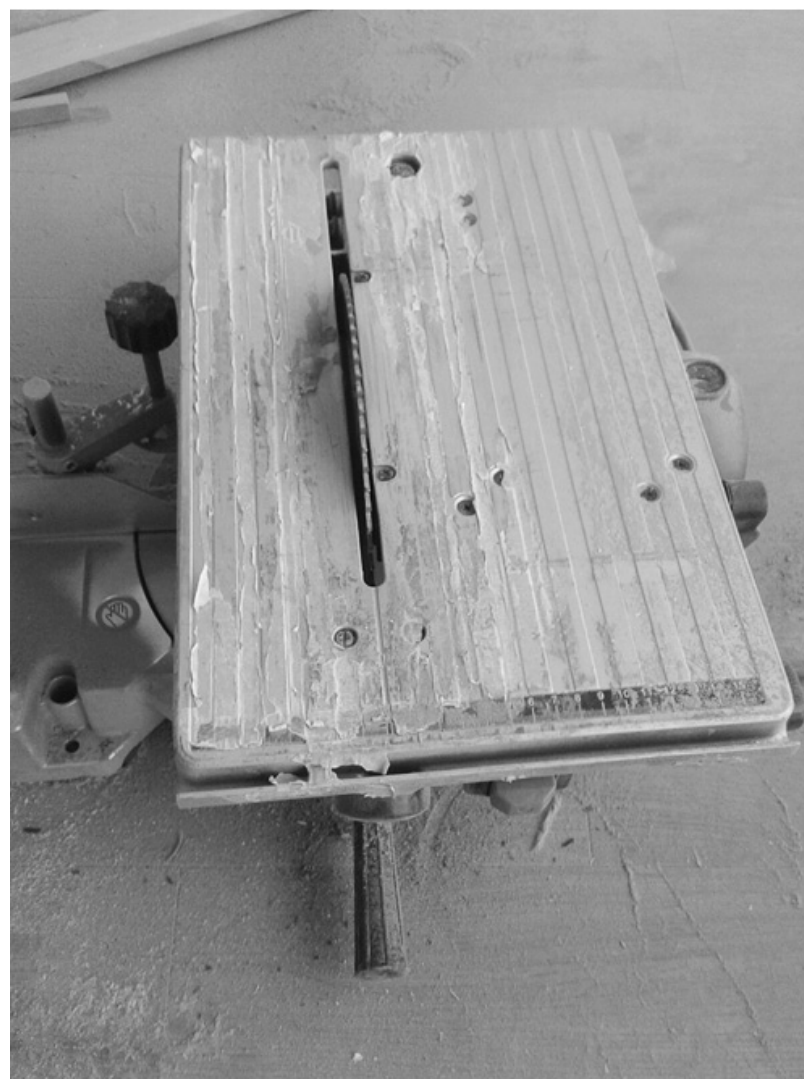

Resim 1. Olgunun iş kazası geçirdiği marangoz makinesi. 
Anabilim Dalımızda hazırlanan raporda olgumuzun bahsi geçen kaza sonucu meydana gelen yaralanmasından ötürü oluşan maluliyetinin hesaplanmasında 11.10.2008 tarihli ve 27021 sayılı Resmî Gazete'de yayımlanan Sosyal Sigortalar Kurumu Sağlık İşlemleri Tüzüğü esas alınmıştır. Şahsın olay anındaki yaşı:54, MGN:6, sağ el başparmak eklem arızası için A cetveli IX. Liste ASN:1B-c-ca, AAÖ:7 (gerekli orantılama yapılarak), SİGS: C olarak alınarak hesaplandığında vücut genel çalışma gücünden kayıp oranının: \% 12,1 (yüzdeonikivirgülbir) olarak hesaplandığı ve 2 (iki) ay süre ile iş göremezlik halinde kaldığı, kanaatinde bulunduğumuz belirtilmektedir.

\section{Tartışma}

İş kazaları; bildirimi zorunlu vakalardır. Bu nedenle; hekimin, iş kazasının karakteristik bulgularını özümsemiş olarak işçi muayenelerini yapması gerekmektedir. 6331 Sayılı Kanun'un 8.maddesinin 4.fikrasında; iş kazası sonucu işçinin ölmesi ya da malul kalması durumunda iş yeri hekiminin ihmali varsa, hekimin görevinin askıya alınaca$\breve{g}_{1}$ belirtilmektedir (1). Kanun çeşitli yaptırımlar uygulanarak iş yasasının çerçevesini oluşturuyorsa da hekimler açısından bazı dezavantajları bulunmaktadır. Yasaya göre ihmal durumlarında hekimin işverene karşı sorumlu olması ve hekimin iş kazaları için gerekli önlem almaması halinde işvereni bakanlığa şikayet etme ödevi bulunmaktadır (1).

Adli vaka niteliğinde olan iş kazalarının etiyolojisinde; uygun olmayan mesai koşulları, deneyimsiz çalışan, dikkatsizlik, yetersiz güvenlik önlemleri ve personel eğitimi önemli bir yer tutmaktadır. Özellikle beceri gerektiren işlerde ince motor fonksiyon sebebiyle daha az korunaklı kullanılan üst ekstremitenin bu tip kazalarda travmaya maruz kalması daha sık olmaktadır.

İş kazaları sonucu maruz kalınan travmalar kalıcı maluliyetlere hatta çalışanın ölümüne neden olabilmektedir. Malul kalan çalışan, iş mahkemeleri aracılığıyla tazminat davası açarak kendisinde mevcut olan maluliyet oranı ve iş göremezlik süresi oranına göre maddi gelir elde etmektedir. Resmi bilirkişilik görevini yürüten, Üniversitelerin bünyesindeki Adli Tıp Anabilim Dalları ve Adli Tıp Kurumu 3. İhtisas Kurulu; maluliyet oranı ve iş göremezlik süresi konularında mahkemelere görüş bildirmektedir. Diğer kaza türlerinde olduğu gibi iş kazaları sonucunda da ortaya çıkabilecek maluliyetlerin raporlanması sürecinde, Adli Tıp Uzmanı mevcut sekeller ile iş kazası arasındaki illiyet bağını titizlikle kurarak çalışanın hak kaybına uğramasını ve iş kazalarının göz ardı edilmesini engellemektedir.

Tüm travma türlerine olduğu gibi iş kazalarına da erkekler daha çok maruz kalmaktadır. Paylaştığımız üç olgudan ikisinin erkek olması bu yönüyle literatürle uyumlu bulunmuştur (13). El yaralanması kaza, yaralama vb. nedenlerle genç yaştaki erkeklerde sıkça görülmektedir. Birinci olgu- muzun yirmili yaşta olması ve el parmaklarında amputasyon meydana gelmesi bu yönüyle literatürle uyumlu bulunmuştur (13). İş kazalarına birçok endüstri sektöründe rastlanabilmektedir. Mobilya sektöründe çalışırken iş kazasına maruz kalması yönüyle üçüncü olgumuz literatürle uyumludur (14). Beceri gerektiren işlerde dominant olan tarafin daha sık olarak kullanılması dominant elin iş kazalarında daha sık travmaya maruz kalmasına neden olmaktadır. Üç olgumuzda da dominant elin yaralandığı göz önüne alındığında çalışmamız literatürle uyumlu bulunmaktadır (15).

İş kazaları; önemli miktarda iş gücü kaybına, maddi zarara, uzamış işe dönüş süresine, kalıcı maluliyetlere ve hatta ölümlere sebep olmaktadır. Adli tıp uzmanının iş kazaları sonucu ortaya çıkabilecek yaralanma karakteristiklerini bilerek, bu tür yaralanmalar hakkında rapor düzenleme konusunda dikkatli olmasının uygun olacağ kanaatindeyiz.

\section{Kaynaklar}

1. www.mevzuat.gov.tr (Erişim tarihi:23.11.2015)

2. www.sgk.gov.tr (Erişim tarihi:06.11.2015)

3. Dağlı B, Serinken M. Acil Servise Başvuran İş Kazalarına Bağ11 Yaralanmalar. JAEM 2012;11:167-70.

4. Gideroğlu K, Sağlam İ, Çakıcı H, Özturan KE, Güven M, Görgü M. El yaralanmalarının epidemiyolojisi. Abant Med J 2012;1(1):13-5.

5. Rinkevich Y, Maan ZN, Walmsley GG, Sen SK. Injuries to Appendage Extremities and Digit Tips:A Clinical and Cellular Update. Developmental Dynamics. 2015;244:641-50.

6. Ünlü RE, Ünlü EA, Orbay H, Şensöz Ö, Ortak T. Ezici el yaralanmaları. Ulus Travma Acil Cerrahi Derg. 2005;11(4):324-28.

7. Bilgin BÇ, Çı̆̆șar G, Kahramanca Ş, Karaca T, Özer S, Türktaș U ve ark. Bir Sanayi Bölgesinde Çalışan İşçilerin El Yaralanmalarının Özellikleri. Kafkas J Med Sci 2013; 3(3):109-12.

8. Oberfeld E, Zwahlen M, Vögelin E. Return to Work after Traumatic Hand Injuries: Medical, Personal and Work-related Factors. Handchir Mikrochir plast Chir 2015; 47(01):44-57.

9. Eriksson M, Karlsson J, Carlsson KS, Dahlin LB, Rosberg HE. Economic consequences of accidents to hands and forearms by $\log$ splitters and circular saws: Cost of illness study. J Plast Surg Hand Surg 2011;45:28-34.

10. Trybus M, Lorkowski J, Brongel L, Hladki W. Causes and consequences of hand injuries. The American Journal of Surgery 2006;192:52-7.

11. Dias JJ, Garcia-Elias M. Hand injury costs. Injury, Int. J. Care Injured 2006;37:1071-7.

12. Şakrak T, Mangır S, Körmutlu A, Cemboluk Ö, Kıvanç Ö, Tekgöz A. 1205 El Yaralanması Olgusunun Retrospektif Analizi. Turk Plast Surg 2009;17(3),134-8.

13. Aslan A, Aslan İ, Özmeriç A, Atay T, Çaloğlu A, Konya MN. Acil El Yaralanmalarında Deneyimlerimiz:5 Y1llık Verilerin Epidemiyolojik Değerlendirmesi. TAF Prev Med Bull 2013;12(5):563-70.

14. Tuncalı D, Toksoy K, Terzioğlu A, Aslan G. Üst ekstremite akut tendon yaralanmaları:Epidemiyolojik değerlendirme. Türk Plast Rekonstr Est Cer Derg 2005;13(2),114-8.

15. Altan L, Akın S, Bingöl Ü, Özbek S, Yurtkuran M. El Yaralanması Ciddiyet Skoru'nun endüstriyel el yaralanmalarında prognozu belirlemedeki rolü. Ulus Travma Derg 2004;10(2):97-101. 